\title{
Chronic instability of the foot and foot geometry: a radiographic study
}

\author{
J. W. K. Louwerens*, A. Z. Ginai ${ }^{\dagger}$, B. van Linge ${ }^{\ddagger}$, C. J. Snijders ${ }^{\S}$ \\ University Cluster of Orthopaedics*, Central Military Hospital, Utrecht, Departments of Radiology and \\ $¥$ Orthopaedics, University Hospital Rotterdam, and $\$$ Department of Biomedical Physics and Technology, \\ Erasmus University Rotterdam, The Netherlands
}

SUMMARY. Multiple factors are involved in chronic lateral instability of the ankle. The geometry of the foot may be of importance. A cavovarus foot may predispose to lateral ligament injuries. In the present study, standardized lateral X-rays were obtained of the feet of patients with chronic instability and of a control group. Four parameters were used: (1) the tarsal index as described by Benink; (2) the talocalcaneal angle; (3) the talometatarsal angle; and (4) the calcaneal angle. No relationship between lateral instability of the foot and foot geometry was found. The talocalcaneal angle as defined in this study was found to be a less appropriate parameter in measuring the longitudinal foot arch.

\section{INTRODUCTION}

Twenty to forty percent of patients who injure the lateral ligament complex of the ankle have residual complaints ${ }^{1,2}$. These include 'giving way', often associated with frequent inversion injuries and a variable amount of pain and swelling. While many factors may be involved in chronic instability, it has been suggested that a foot with cavovarus build is more prone to lateral ligament injuries. ${ }^{3,4}$ From a biomechanical point of view it seems likely that a foot with a cavovarus configuration inverts more readily than a plantigrade foot.

In this study, 4 geometric foot indices were measured on standardized lateral X-rays in order to (1) establish a relationship between foot build and chronic lateral instability and (2) evaluate the interrelationship between these foot indices.

\section{PATIENTS AND METHODS}

\section{Patients and control groups}

Twenty-two patients with bilateral and 11 patients with unilateral chronic ankle instability symptoms were examined. The patients were recruited consecutively from the orthopaedic outpatient department. All patients complained of frequent inversion injuries with variable amount of 'giving way', swelling, pain

Correspondence to J. W. K. Louwerens MD, University Cluster of Orthopaedies, Central Military Hospital, P.O. Box 90.000, 3509 AA Utrecht, The Netherlands. and reduced level of activity. In 28 patients, symptoms had existed for more than 3 years and in 5 patients, more than 1 year. 'Giving way' was present while walking on even ground in 28 feet, and while walking on uneven ground in 22 more feet. In 3 feet, problems existed only during sporting activity and in 2 feet, pain was constantly present. The control group consisted of 10 subjects with no such symptoms. The number, age, sex, height and weight of the patient and control groups are shown in Table 1.

\section{Methods}

A special device was used to obtain standardized lateral radiographs of the foot in a neutral position with full weightbearing (Fig. 1).

A low platform was provided with a cassette holder. Parallel to the cassette were two transparent perspex plates between which the foot was placed on a $2 \mathrm{~cm}$ elevation with the lateral border parallel to the plates. In each perspex plate a small pellet (diameter 2 $\mathrm{mm}$ ) could be adjusted in a vertical direction along a scale. These pellets were adjusted to the same height as the talar neck after palpation of the sinus tarsi. The $\mathrm{X}$-ray beam was centred on the pellets. The distance between focus and film was $1 \mathrm{~m}$. Radiographs were taken of each foot. They were accepted if the two pellets were completely aligned and when no part of the first metatarsal bone or the tarsus was outside the film. In a few cases a new radiograph had to be made.

The tarsal index was determined and three angles (1) the lateral talo-calcaneal, (2) the talo-metatarsal and (3) the calcaneal angle were measured (Fig. 2). 
Table 1 The number, age, sex, height and weight of the patient and control groups

\begin{tabular}{lccc}
\hline & $\begin{array}{l}\text { Patients } \\
\text { Bilateral } \\
\text { symptomatic }\end{array}$ & $\begin{array}{l}\text { Unilateral } \\
\text { symptomatic }\end{array}$ & $\begin{array}{l}\text { Controls } \\
\text { Bilateral } \\
\text { asymptomatic }\end{array}$ \\
\hline Number and gender & $22(7 \mathrm{M}, 15 \mathrm{~F})$ & $11(3 \mathrm{M}, 8 \mathrm{~F})$ & $10(4 \mathrm{M}, 6 \mathrm{~F})$ \\
$\begin{array}{l}\text { Age in years } \\
\text { (mean } \pm \text { SD and range) }\end{array}$ & $31 \pm 13.6$ & $30 \pm 9.5$ & $30 \pm 7.4$ \\
$\begin{array}{l}\text { Height in cm } \\
\text { (mean } \pm \text { SD and range) }\end{array}$ & $(19-66)$ & $(19-45)$ & $(18-40)$ \\
$\begin{array}{l}\text { Weight in kg } \\
\text { (mean } \pm \text { SD and range) }\end{array}$ & $(165-201)$ & $176 \pm 6.6$ & $177 \pm 12.9$ \\
\hline
\end{tabular}

Fig. 1 (A) Lateral and (B) frontal views of the set-up used in order to obtain standardized lateral radiographs of the foot. Pellets on both sides of the foot are adjusted to the same height as the tala neck and the X-ray beam is centred on these pellets.

$\mathbf{A}$

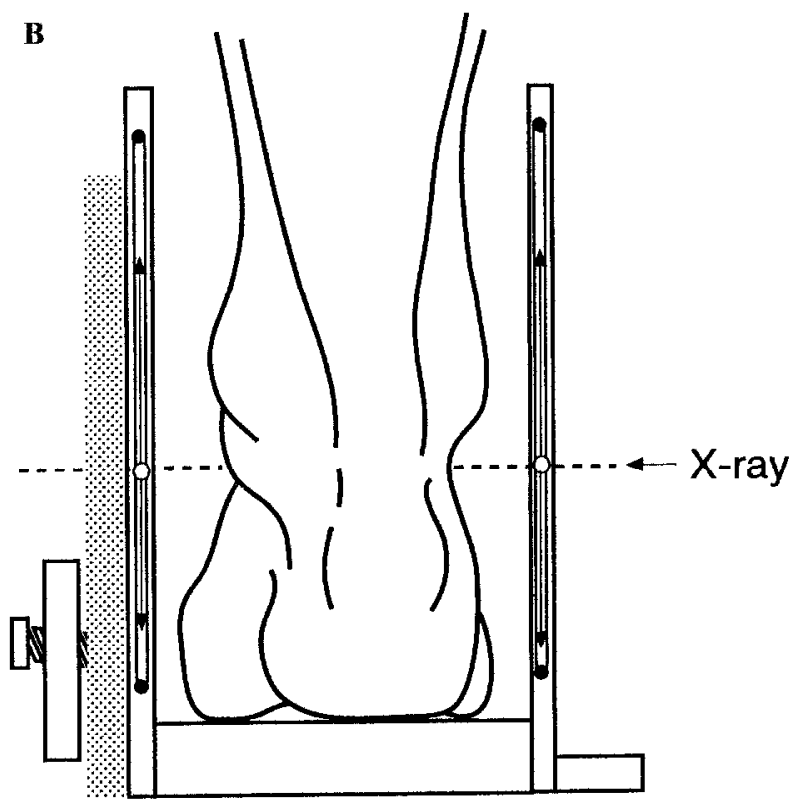



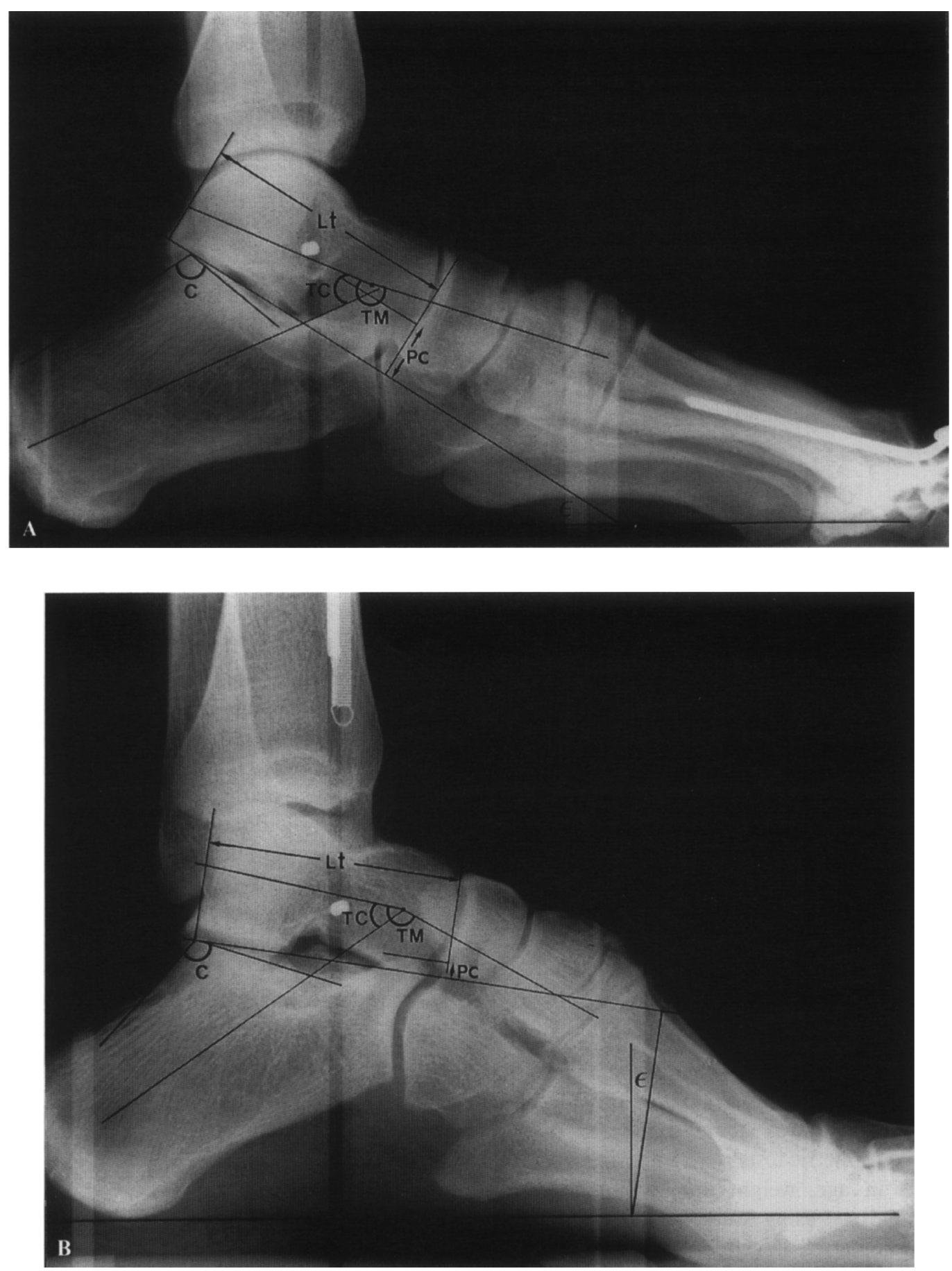

Fig. 2 Radiographs of (A) a foot with a slightly flattened longitudinal arch in comparison with (B) a foot with a high longitudinal arch.

Benink' $\mathrm{s}^{3}$ tarsal index (TI) is based on the angle of inclination of the talocalcaneal joint and on the overlap of the head of the talus and the calcaneum (PC). The angle of the talocalcaneal joint $(\mathrm{E})$ is determined by the line drawn tangential to the posterior articular surface of the calcaneum and the anterior articular surface at the underside of the head of the talus and a line parallel to the platform. PC in $\mathrm{mm}$ is divided by the length of the talus (Lt) in $\mathrm{mm}$. The tarsal index is given as $\mathrm{TI}=100 \times \mathrm{PC} / \mathrm{Lt} \times \operatorname{tgE}$. As will be discussed later, an increase of inversion (cavovarus) of the tarsus results in a decrease of PC and decrease of the angle $\mathrm{E}$ and thus results in a decrease of TI.

The lateral talocalcaneal angle (TC) was defined as the angle between the line through the posterior articular margin of the talar trochlea and the midpoint of the caput tali (the talar line) and the longitudinal line through the calcaneum. Hindfoot cavus is characterized by a more vertical position of the calcaneum, thus a large angle is measured on feet with a high arch. ${ }^{5}$

We used the modification of Larsen \& Angermann ${ }^{4}$ of the talometatarsal angle (TM) proposed by Gould. ${ }^{6}$ 
Table 2 TI, TC, TM and C angles, comparing the symptomatic feet of patients (both unilateral and bilateral) with feet of the control group. Differences were never statistically significant

\begin{tabular}{|c|c|c|c|c|c|c|c|}
\hline & & \multicolumn{3}{|c|}{ Symptomatic } & \multicolumn{3}{|c|}{ Asymptomatic } \\
\hline & & Mean & SD & Range & Mean & SD & Range \\
\hline \multirow{2}{*}{ TI } & $\mathrm{R}$ & 5.9 & 4.1 & $0.6-16.7$ & 6.3 & 2.8 & $2-11.2$ \\
\hline & $\mathrm{L}$ & 6.8 & 3.4 & $1.4-15.2$ & 6.7 & 2.7 & 0.49 .8 \\
\hline \multirow{2}{*}{ TC } & $\mathbf{R}$ & 46.8 & 4.3 & $38-54$ & 47.8 & 4.1 & $42-54$ \\
\hline & L & 44.6 & 4.5 & $36-54$ & 45.0 & 5.6 & $3.5-56$ \\
\hline \multirow{2}{*}{$\mathbf{T M}$} & $\mathbf{R}$ & 171 & 10.9 & $160-184$ & 174 & 5.9 & $166-186$ \\
\hline & $\mathbf{L}$ & 174 & 6.0 & $160-186$ & 174 & 5.3 & $162-183$ \\
\hline \multirow{2}{*}{$\mathrm{C}$} & $\mathrm{R}$ & 111 & 7.8 & $98-125$ & 112 & 9.5 & $98-128$ \\
\hline & $\mathrm{L}$ & 110 & 10.3 & $96-125$ & 111 & 8.8 & $98-125$ \\
\hline
\end{tabular}

TM is the angle between the talar line described above, and a line through the midpoint of caput tali and the midpoint of the base of the first metatarsal. A small angle implies a high arch.

$\mathrm{C}$ represents the angle between the posterior subtalar articular margin and the posterosuperior surface of the calcaneum. A large angle would be seen in feet with high arches. ${ }^{7}$

All the measurements were performed by the same examiner.

\section{Statistics}

The data were analysed using SPSS/PC+, version 3.1. The variables were examined for normality. For each test, a $P$ value of $\leq 0.05$ was considered significant. A logarithmic transformation was applied on variables with a distribution that was skewed to the right before analyses with parametric tests were performed.

Differences in age, weight and height between groups were analysed using Student's $t$ test. To test if groups were comparable in gender a $\chi^{2}$ test was used.

When analysing differences between groups for TI, TC, TM and C, the symptomatic fect of all paticnts (unilateral as well as bilateral) were compared with asymptomatic feet of the controls (Student's $t$ test or Mann-Whitney U test; this was done for left and right feet separately). Secondly, a comparison was made between the asymptomatic feet and the symptomatic feet of patients with unilateral instability, using the asymptomatic feet as controls.

Correlations between age, weight, height and the measured variables (TI, TC, TM and C) were evaluated by means of Pearson's correlation coefficiency. The same test ws used to determine correlations between the variables TI, TC, TM and C. Relationship between these variables and gender were tested using Student's $t$ test.

\section{RESULTS}

The patient and control groups were comparable regarding gender, age, height and weight. No statistically significant differences between symptomatic and asymptomatic feet regarding TI, TC, TM and $\mathrm{C}$ were found (Table 2), neither between the patient and control group, nor within the unilateral group.

Statistically significant positive correlations were found for both right feet and left feet between TI and TM and for right feet between TI and TC (Table 3). For right feet statistically significant negative correlations existed between $\mathrm{C}$ and all three other variables and the same was found between $\mathrm{C}$ and $\mathrm{TI}$ for left feet. A tendency towards statistically significant negative correlations between $\mathrm{C}$ and $\mathrm{TC}$ and between $\mathrm{C}$ and TM was found for left feet.

There was no significant correlation between the variables age, height and weight and the measured variables TI, TC, TM and C. A statistically significant difference was found between men and women for the

Table 3 Correlations between the different variables TI, TC, $\mathrm{TM}$ and $\mathrm{C}$

\begin{tabular}{|c|c|c|c|c|}
\hline \multicolumn{5}{|c|}{ Right feet } \\
\hline & TI & $\mathrm{TC}$ & TM & $\mathrm{C}$ \\
\hline TI & & $\begin{array}{l}0.38 \\
P=0.011^{*}\end{array}$ & $\begin{array}{l}0.66 \\
P=0.000 *\end{array}$ & $\begin{array}{l}-0.57 \\
P=0.000^{*}\end{array}$ \\
\hline TC & $\begin{array}{l}-0.04 \\
P=0.790\end{array}$ & & $\begin{array}{l}0.25 \\
P=0.110\end{array}$ & $\begin{array}{l}-0.55 \\
P=0.000^{*}\end{array}$ \\
\hline TM & $\begin{array}{l}0.71 \\
P=.000^{*}\end{array}$ & $\begin{array}{l}0.12 \\
P=0.430\end{array}$ & & $\begin{array}{l}-0.36 \\
P=0.018^{*}\end{array}$ \\
\hline $\mathrm{C}$ & $\begin{array}{l}-0.36 \\
P=0.017^{*}\end{array}$ & $\begin{array}{l}-0.29 \\
P=0.059^{* *}\end{array}$ & $\begin{array}{l}-0.30 \\
P=0.054^{* *}\end{array}$ & \\
\hline
\end{tabular}

* = statistically significant.

** = tendency towards significancy. 
variable TC for both left $(t=2.62$, d.f. $=41, P=$ $0.012)$ and right feet $(t=2.35$, d.f. $=41, P=0.023)$. Women were found to have lower values of TC.

\section{DISCUSSION}

Functional anatomical studies have demonstrated how the foot in the weightbearing situation moves from a neutral more or less pronated position into a cavovarus position during inversion..$^{3,8-10}$ The talus rotates posterolaterally out of the socket of the navicular bone and 'mounts' the calcaneum (Fig. 3). On a lateral view, the overlap of the head of the talus and the front of the calcaneum will decrease and the talocalcaneal angle will also decrease. From a biomechanical point of view it is likely that a cavovarus foot is more prone to lateral instability as a smaller momentum is needed to enforce further inversion. This was proposed by Benink ${ }^{3}$ who introduced a tarsal index based on a lateral X-ray for evaluating cavovarus; others have also supported this relationship. ${ }^{11-15}$

On clinical examination, we found that cavovarus feet were more frequent in the patient group and we expected to find radiological differences between the patient and control group. In 6 out of 55 symptomatic feet a TI below 2.0 was measured, while in all 20 feet of the control group the TI was higher than 2.0. However, no statistically significant difference between the groups could be demonstrated (Table 2). As far as the values of TI are concerned our data were comparable with those of Larsen \& Angermann. ${ }^{4}$

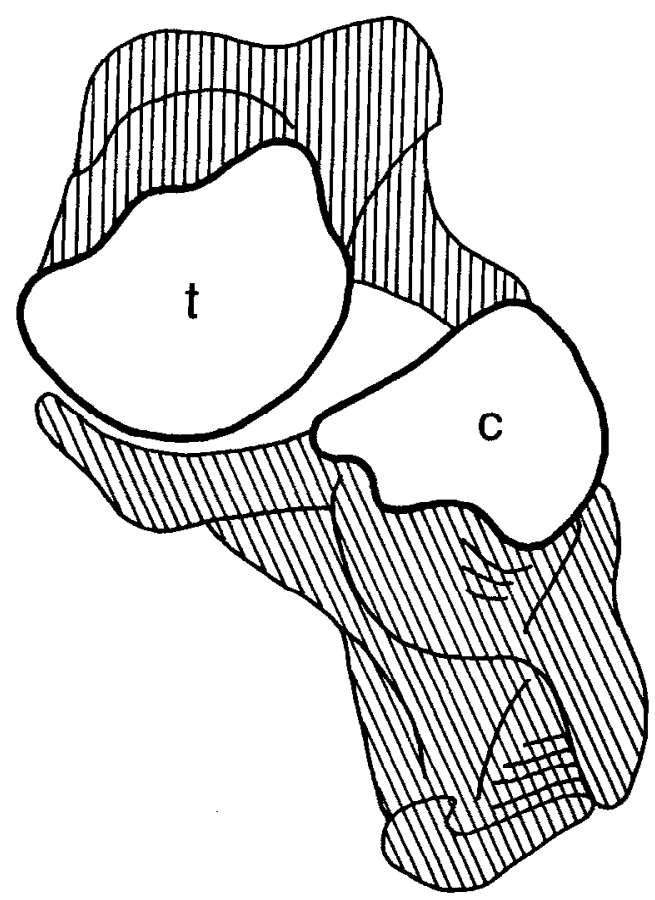

A
In contrast with our results, they found lower values of TI for their patients and a statistically significant difference between the groups. Possibly this can be explained by the fact that they performed their measurements on the fect in a non-weightbcaring position and with a different patient selection.

Three of the 6 symptomatic feet with a TI beneath 2.0 were the symptomatic foot of a patient with unilateral complaints. Two of the 3 asymptomatic feet of these patients also had a high arch with a TI beneath 2.0 (i.e. 0.9 and 0.4 ). Thus it seems that a cavovarus build is not a dominant factor and is only one of the multiple factors playing a role in chronic instability.

As the medial foot arch lowers, the TI will increase and a positive correlation with $\mathrm{TM}$, which also increases, is to be expected (Table 3). A higher $\mathrm{C}$ angle is said to be related with a high arch of the foot and the negative correlation between this angle and both TI and TM is thus understandable. While others ${ }^{4}$ report that the $\mathrm{TC}$ angles in feet with higher arches are to be found higher, implying a negative correlation between TC and both TI and TM and a positive correlation between $\mathrm{TC}$ and $\mathrm{C}$, our findings are closer to finding the contrary. With cavovarus the calcaneum most often assumes a vertical position, but as illustrated (Fig. 2) the talus moves upward, and as a result the TC angles of a foot with a lower arch and of a foot with a high arch can be equal. With increase of varus, the TC angles might even become smaller as reported by Keim \& Ritchie, ${ }^{16}$ who find an increase of the 'lateral TC angle' when the patient has a valgus heel or a calcaneal foot.

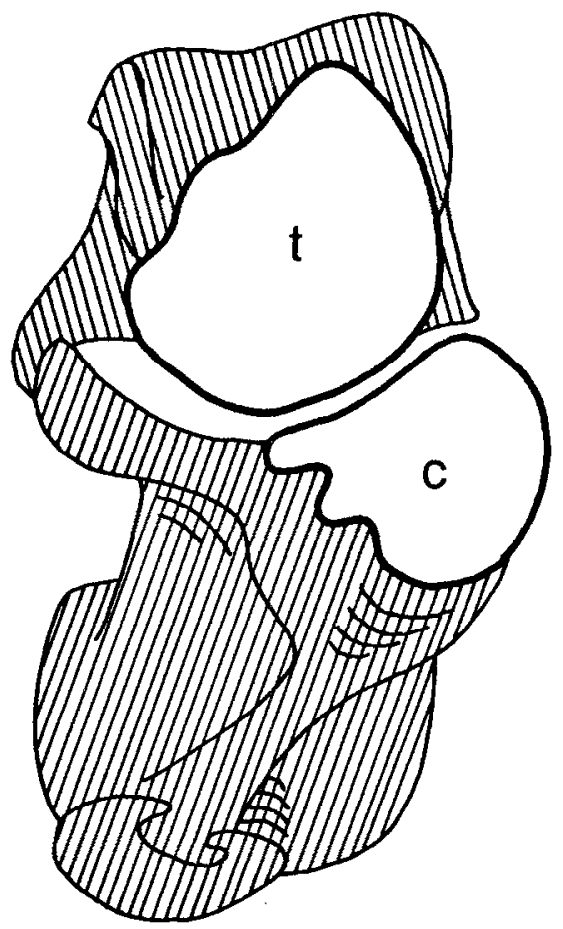

B inversion

Fig. 3 Frontal vicw on the talocalcaneal joint complex in (A) a neutral position and (B) after inversion of the foot. 
In conclusion, we are unable to establish a relationship between chronic lateral instability of the foot and foot geometry. The TC angle as defined in the present study is a dubious parameter for measuring the longitudinal arch of the foot. In daily orthopaedic practice the TM angle seems to be a better measure of cavus of the foot.

\section{ACKNOWLEDGEMENTS}

The authors are indebted to René Verheij (Department of Biomedical Physics and Technology) and Paul G. M. Mulder (Department of Epidemiology and Biostatistics, Erasmus University Rotterdam) for their help in performing the statistical analysis. We also thank Monique Scheunemann and Rolf Raaymakers (Department of Radiology, University Hospital Rotterdam) for their assistance while making the radiographs.

\section{REFERENCES}

1. Freeman M A R, Dean R E, Hanham I W F. The etiology and prevention of functional instability of the foot. J Bone Joint Surg [Br] 1965; 47B: 678-685.

2. Hansen $H$, Damholt V, Thermansen N. Clinical and social status following injury to the lateral ligaments of the ankle. Acta Orthop Scand 1979; 50: 699-704.

3. Benink R J. The constraint-mechanism of the human tarsus. Acta Orthop Scand 1985; 215 (suppl).
4. Larscn E, Angcrmann P. Association of ankle instability and foot deformity. Acta Orthop Scand 1990; 61: 136-139.

5. Samilson R L, Dillin W. Cavus, cavovarus, and calcaneocavus, an update. Clin Orthop 1983; 177: 125-132.

6. Gould N. Evaluation of hyperpronation and pes planus in adults. Clin Orthop 1983; 181: 37-45.

7. Gamble F O, Yale I. Pes Cavus. In: Clinical foot roentgenology, Baltimore: Williams and Wilkins, 1966: 215-219.

8. Huson A. Een ontleedkundig, funktioneel onderzoek van de voetwortel. PhD Dissertation, University of Leiden, Leiden, Netherlands, 1961.

9. Huson A. Functional anatomy of the foot. In: Jahss M H, ed. Disorders of the foot and ankle, vol. 1, 2nd ed. Philadelphia: Saunders, 1991: 409-432.

10. Van Langelaan E J. A kinematical analysis of the tarsal joints. Acta Orthop Scand 1983; 204 (suppl).

11. Ayres M J, Bakst R H, Baskwill D F, Pupp G P. Dwyer osteotomy: a retrospective study. J Foot Surg 1987; 26: 322-328

12. Bremer $\mathbf{S ~ W}$. The unstable ankle mortise - functional ankle varus. J Foot Surg 1985; 24: 313-317.

13. Lassiter T E, Malone T R, Garrett W E. Injury to the lateral ligaments of the ankle. Orthop Clin North Am 1989; 20 629-639.

14. Subotnick S I. The biomechanics of running. Implications for the prevention of foot injuries. Sports Med 1985; 2: 144-153.

15. Vidal J, Fassio B, Buscayret Ch, Escare Ph, Allieu Y. Instabilité externe de la cheville. Importance de I'articulation sous-astragalienne: nouvelle technique de réparation. Rev Chir Orthop 1974; 60: 635-642.

16. Keim H A, Ritchie G W. Weight-bearing roentgenograms in the evaluation of foot deformities. Clin Orthop 1970; 70: 133-136. 